\title{
EMEDICINE AND COMPUTER LITERACY
}

\author{
L. Despotova-Toleva, K. Slavejkov*, K. Trifonova \\ Department of Ophthalmology and General Medicine, Medical Faculty, Trakia University, \\ Stara Zagora, Bulgaria
}

\begin{abstract}
Introduction: E-medicine has become an integral part of modern health care. Besides the well-known advantages, there are barriers to its effective use. One of which is the level of computer literacy of consumers.

Aims and objectives: To examine the level of computer literacy among doctors and medical students through shortlisted issues of basic questionnaire

Materials and methods: Target groups of doctors and medical students from Bulgaria, USA, Hungary, Greece, Italy and Austria. Statistical processing with SPSS 17

Results: More than half of the participants in the Bulgarian group $(54.71 \%)$ declare participation in courses or training, with no difference between doctors and medical students (a result similar to that of the Italian group). Even fewer of them (30\%) can confirm that training with a certificate. More than half of the bulgarian doctors and students do not know what broadband is - the lowest score of all groups. These issues are discussed in the context of some demographic and qualifications of the participants.

Discussion: Given the new realities of global e-health and job requirements in terms of eHealth Bulgarian doctors and students need targeted training in this area to be able to practice successfully in the coming decades.
\end{abstract}

Key words: ehealth, general practitioners

Introduction: The development of information and communication technologies gradually covers all aspects of medicine. E-medicine has become an integral part of modern health care. Besides the well-known advantages, there are a number of difficulties and barriers to its effective use. One of which is the level of computer literacy of consumers.

Studies show that training opportunities for medical professionals significantly expand. Elearning as part of emedicine provides an excellent opportunity for learning regardless of time and place. In a study Avitzur and colleagues report that low computer literacy was a major barrier to full use of online resources and even pushed away a significant proportion of consumers from further eLearning usage [1].

After a web-based survey among graduate otorhinolaringologists Fraser and colleagues report high or very high self-assessment of

\footnotetext{
* Correspondence to: $K$. Slavejkov, Department of Ophthalmology and General Medicine, MF to Trakia University, Stara Zagora, Bulgaria, kirilslaveykov@gmail.com,tel.: 0886712078
}

computer literacy among respondents [2]. Most of them are dissatisfied with the telemedicine elements presented to them, and find them lacking compared to their knowledge.

The difference in assessment of computer literacy does not occur only with doctors, but also for nurses. Kezias' team examines computer literacy among dermatological nurses and also found misalignment between generations. In the results, however, they reported that after appropriate training nurses have significantly greater access to modern technology, which improves the quality of patient care. [5]

Key predictors of computer literacy according to Hoss and team are the level of education and age of user. Respondents with a bachelor's or higher degree of education show higher results, which is also observed among younger participants [4].

A similar study conducted by Rababi and team, who report similar results. A high percentage of students have personal computer $(77.1 \%)$ while their knowledge vary from minimal - the ability to work on the Internet to in-depth 
knowledge of software and hardware options. The team found a direct link between the possession of a personal computer, participation in computer-based training and the level of computer literacy. [6]

The team of Gazibara examines the level of computer literacy among the population of Serbia. Their results showed a significant decline in the use of computers after 65 years of age. Of the respondents over 65 , only $20.2 \%$ use a computer, of which only $23.7 \%$ can cope with medical information inquiries. The key predictors of computer literacy according to the team are age, financial status and education. [3]

Despite the existence of "digital divide" between generations, it can be overcome. The team of Serdar explore the use of personal digital assistants (PDA). Although there is no perfect software and initial problems exist in the use of assistants, even participants with lower computer literacy within a few weeks shows a good level of absorption and use of emedicine resources [7].

Aims and objectives: To examine the level of computer literacy among doctors and medical students through shortlisted issues of basic questionnaire created for the purpose of study "e-medicine: modern aspects, problems and solutions" (competitive funding from the Ministry of Education, grant No1531 / 05.

Materials and methods: Target groups of doctors and medical students from Bulgaria, USA, Hungary, Greece, Italy and Austria. Statistical processing with SPSS 17 selected questions aimed at determining the level of computer literacy.

Results: More than half of the participants in the Bulgarian group $(54.71 \%)$ declare participation in courses or training, there is no difference between doctors and medical students (a result similar to that of the Italian group) (Figure 1). When working in a ehealth setting those who have not passed such training would encounter significant difficulties. Given that more than half of Bulgarian doctors have not undergone even basic level of training for computer skills, their job compared to other countries would be not just difficult, but it could even compromise the health care system.

Even fewer of them (30\%) can confirm that training certificate obtained (Figure 2). In the context of the aforementioned complications, it is important for the skills acquired by doctor to be graded and proven.

In terms of Internet access in the workplace Bulgaria is last of the countries studied with only $60 \%$. Compared to it in other countries it is above $90 \%$ and even up to $100 \%$ in the US. Lack of access to the Internet in the workplace was associated with reduced motivation for further training and work in conditions of eHealth (Figure 3).

Answer this question show a discrepancy in the declared US $100 \%$ Internet access in the workplace and participation in computer training courses and their knowledge of the topic, with only 54.67 percent know the definition of broadband. The results are similar to those in Bulgaria, while in other countries it is over $80 \%$.

Discussion: Our results are similar to those in other similar researches. The presence of the "digital divide" is a fact, and key factors for its existence are differences in age, financial situation and education. Given the new realities of global e-health and job requirements in terms of eHealth Bulgarian doctors and students need targeted training in this area to be able to practice successfully in the coming decades.

\section{Have you ever participated in computer training courses?}

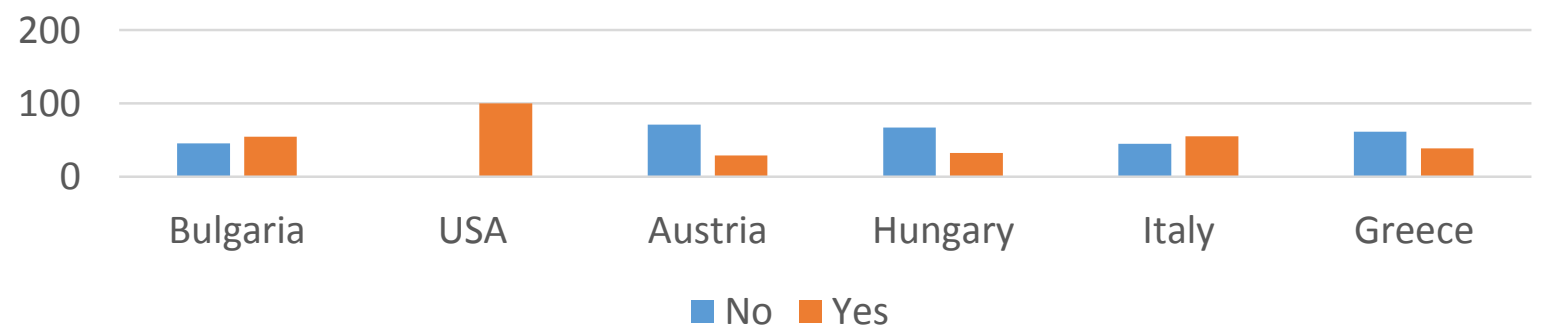

Figure 1 


\section{Do you have a document confirming this}

\section{training?}

100

0

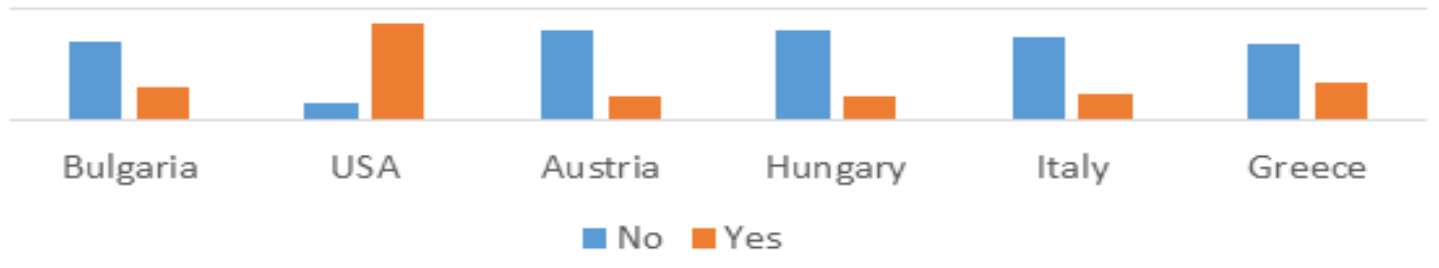

Figure 2

\section{Do you have Internet access in your workpalce?}

0

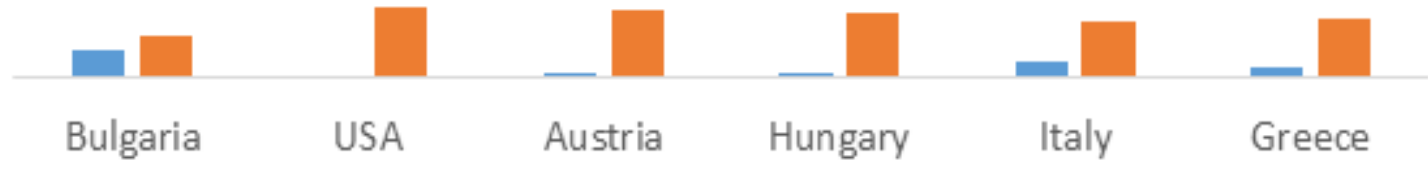

No $\quad$ Yes

Figure 3

\section{Do you know what the term "broadband internet" means?}

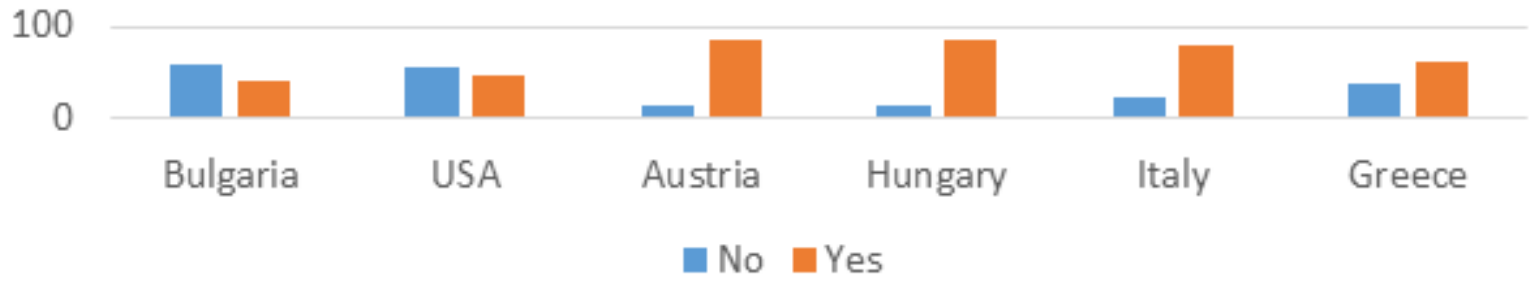

Figure 4

\section{REFERENCES}

1. Avitzur, Orly. "ONLINE CME: LEARNING OPPORTUNITIES FOR NEUROLOGISTS EXPAND." Neurology Today 2.9 (2002): 26-27.

2. Fraser, L., et al. "Current use of and attitudes to e-learning in otolaryngology: questionnaire survey of UK otolaryngology trainees." The Journal of Laryngology \& Otology 125.04 (2011): 338-342.

3. Gazibara T, Kurtagic I, Kisic-Tepavcevic D, Nurkovic S, Kovacevic N, Gazibara T, Pekmezovic T. Computer and online health information literacy among Belgrade citizens aged 66-89 years. Health Promot Int. 2015 Jan 9. pii: dau106.

4. Hoss, Brenda, and Diane Hanson. "Evaluating the evidence: web sites." AORN journal 87.1 (2008): 124-141.
5. Lilly, Kezia D., and Carole Eldridge. "Healthcare Informatics in 21st-Century Nursing: Are Dermatology Nurses Prepared?." Journal of the Dermatology Nurses' Association 4.3 (2012): 188-194.

6. Robabi H, Arbabisarjou A. Computer literacy among students of zahedan university of medical sciences. Glob J Health Sci. 2015 Jan 1;7(4):40274. doi: 10.5539/gjhs.v7n4p136.

7. Serdar, Muhittin A., Mustafa Turan, and Murat Cihan. "Rapid access to information resources in clinical biochemistry: medical applications of personal digital assistants (PDA)." Clinical and experimental medicine 8.2 (2008): 117-122. 